\title{
A study of breast-feeding practices among rural women
}

\author{
Patel 5. ${ }^{1}$, K Nigam K. ${ }^{2 *}$, Babu G. ${ }^{3}$, Murty Kadali . $^{4}$ \\ DOI: https://doi.org/10.17511/ijphr.2020.i06.02 \\ 1 Santosh Patel, Assistant Professor, Department of Community Medicine, RKDF Medical College and Research Centre, Bhopal, Madhya \\ Pradesh, India. \\ 2* Kamlesh K Nigam, Associate Professor, Department of Community Medicine, RKDF Medical College and Research Centre, Bhopal, Madhya \\ Pradesh, India. \\ 3 G. Chitti Babu, Assistant professor, JNU Medical College and Hospital, Jaipur, Rajasthan, India. \\ 4 SLDV Ramana Murty Kadali, Associate Professor, Department of Pharmacology, JNU Institute of Medical Sciences and Research Center, \\ Jaipur, Rajasthan, India.
}

Introduction: Breastfeeding is an unequalled way of providing ideal food for the healthy growth and development of infants. As per the national family health survey-3 (NFHS-3), only $46 \%$ of the Indian infants between 0 and 6 months are exclusively breastfed. Hence the following study was done to know the practice of breastfeeding in mothers of rural and urban areas of India. Materials and Methods: The study was conducted in a rural and urban area, which is under the administrative control of a tertiary care hospital. All lactating mothers having babies up to 1 year were included in the study. Results: The mean age was 26.73 years (SD $=2.53$ ), and $40.4 \%$ of mothers were below 20-24 years of age. A large proportion (77.8\%) were of the Hindu faith. Most mothers had education beyond primary school. $35.1 \%$ of participants were mothers of 2 or more children. A large percentage $(74.7 \%)$ of study participants were delivered in a hospital. Exclusive breastfeeding was practiced by $73.1 \%$ of mothers. $78.3 \%$ of a mother gave first breast milk i.e. colostrum to their new-borns. Still, $46.3 \%$ of mothers feed their child with honey, Ghutti, plain water, artificial milk, sugar water, etc., before starting breastfeeding. Conclusions: The counseling should be continued after the delivery of the baby for continuous education to the mother about the proper care of newborn, initiation of breastfeeding, the information regarding the advantages and duration of breastfeeding, the importance of colostrum feeding, the timing of weaning needs to be provided.

Keywords: Breastfeeding, Colostrum, Practices, Rural women

\section{Corresponding Author}

Kamlesh K Nigam, Associate Professor, Department of Community Medicine, RKDF Medical College and Research Centre, Bhopal, Madhya Pradesh, India. Email: faheem.mubeen@yahoo.co.in

\section{How to Cite this Article}

Patel S, Nigam K K, Babu G C, Kadali S R M. A study of breast-feeding practices among rural women. Public Health Rev Int J Public Health Res. 2020;7(6):51-57.

Available From

https://publichealth.medresearch.in/index.php/ijphr/ article/view/140
To Browse

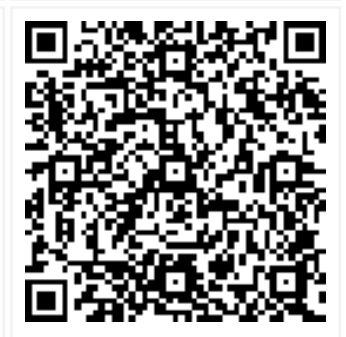

Review Round 1
2020-11-09
Funding
Nil
(C) 2020 by Santosh Patel, Kamlesh K Nigam, G. Chitti Babu, SLDV Ramana Murty Kadali and Published by Siddharth Health
Research and Social Welfare Society. This is an Open Access article licensed under a Creative Commons Attribution 4.0 International License https://creativecommons.org/licenses/by/4.0/ unported [CC BY 4.0].
Manuscript Received 2020-10-29

Conflict of Interest No
- Funding

Review Round 2 2020-11-21

Ethical Approval
Review Round 3

Accepted 2020-12-15

Note 


\section{Introduction}

Appropriate Infant and Young Child Feeding (IYCF) practices are essential for optimal growth, cognitive development, and overall well-being in early vulnerable years of life. Breastfeeding though is a natural act; it is a behavior that needs to be learned. Mothers and other caregivers need active assistance for optimum breastfeeding practices.

The Global Strategy for Infant and Young Child Feeding describes the essential interventions to promote, protect, and support exclusive breastfeeding [1]. Malnutrition contributes to about $60 \%$ of under-five mortality worldwide annually and over two-thirds of these are due to inappropriate feeding practices [2]. An analysis showed that appropriate breastfeeding and complementary feeding practices can alone prevent under-five deaths by $19 \%$ [3].

The World Health Organization (WHO) recommends exclusive breastfeeding for the first six months of life and the addition of complementary feeds from six months onwards, with continued, breastfeeds until at least two years of age [4]. Also, WHO and UNICEF had jointly adopted the Innocenti Declaration on the protection, promotion, and support of breastfeeding.

Exclusive breastfeeding means no drinks like honey, water, glucose water, gripe Water, juices, vitamins, animal or powdered milk, or foods other than breast milk are given for the first 6 months to the babies [5].

Apart from exclusive breastfeeding initially, the time of introduction, content, and consistency of complementary feeds are critical for early nutrition. The early introduction of complementary feeds before the age of six months can lead to the displacement of breast milk and increased risk of infections, besides the babies being physiologically immature.

Similarly, inadequate and inappropriate complementary feeding with unhygienic practices leads to recurrent and persistent infections and malnutrition which is followed by growth retardation, immunodeficiency, and eventually fatal outcomes.

This is a concern for the Indian scenario, where previous studies have suggested an inability to maintain exclusive breastfeeding and the late introduction of complementary feeds [6].
Evidence-based studies have stressed the importance of human milk and concluded that infant feeding should be considered as a basic health issue rather than a lifestyle choice [7].

Multiple efforts are being envisaged to improve feeding practices in children. WHO and the United Nations Children's Fund (UNICEF) launched the Baby-Friendly Hospital Initiative in 1992, Integrated Management of Childhood Illness (IMCI) in the mid1990s, and IYCF in 2002 which stress the importance of breastfeeding.

All these programs have been adopted by India in the last one to two decades to promote appropriate feeding practices in children under-five years. Multiple factors are responsible for this slow improvement in nutritional health indicators in India. According to the World Bank report, India's Integrated Child Development Services (ICDS) needs to undergo significant changes to address the current malnutrition crisis in India [8].

India hosts more than one-third of the world's children who are wasted. Of under-five children in India, $43 \%$ are underweight and $48 \%$ are stunted due to chronic undernutrition. Only $25 \%$ of newborns were put to the breast within one hour of birth and $46 \%$ are exclusively breastfed [9]. In India, more than 11 lakh babies die during the first month of life, and another 5 lakhs from 2 to 12 months of age. Neonatal mortality accounts for almost $40 \%$ of all under-five deaths and nearly $60 \%$ of infant deaths as per national family health survey-4 (NFHS-4), only $46 \%$ of the Indian infants between 0 and 6 months are exclusively breastfed [10].

Appropriate breastfeeding and complementary feeding practices depend on accurate information and support from the family, community, and healthcare system. Inadequate knowledge about feeding practices is an equally important determinant of malnutrition, as is the lack of adequate and hygienic food. However, despite all the efforts deployed as information, education, or training campaigns, the prevalence of proper feeding practices remains low.

As there is a paucity of literature on the feeding practices in this region, the present study was undertaken to assess the feeding practices of mothers having children under-five years of age. The interaction of sociodemographic variables with feeding practices and associations of childhood morbidity were studied. 
Hence the following study was done to know the practice of breastfeeding in mothers of rural and urban areas in central India.

\section{Materials and Methods}

The study was conducted in a rural area, which is an adopted area under the administrative control of the Community Medicine Department, RKDF Medical College, and Research Centre. The study was part of a larger study conducted for 1 year. All lactating mothers attending rural and urban health training center OPD during the given period were eligible for the study.

Mothers were interviewed on a predesigned pretested semi-structured 'questionnaire'. The questionnaire included socio-economic and demographic data, details on the initiation and duration of breastfeeding, details on artificial feeding and weaning practices, and newborn care practices. A total of 361 mothers were interviewed during the period. Statistical analysis was done using SPSS software.

\section{Results}

\section{Sociodemographic information}

Table 1 presents the sociodemographic information of study participants. The mean age was 26.73 years $(S D=2.53)$, and $40.4 \%$ of mothers were below 20-24 years of age. A large proportion $(77.8 \%)$ were of the Hindu faith. Most mothers had education beyond primary school. $55.9 \%$ of mothers living in cemented pakka house. $35.1 \%$ of participants were mothers of 2 or more children. A large percentage $(74.7 \%)$ of study participants delivered in a hospital in table 1.

Table-1: Sociodemographic characteristics of the study participants.

\begin{tabular}{|l|l|l|}
\hline \multicolumn{1}{|c|}{ Characteristics } & Frequency & \multicolumn{1}{c|}{ Proportion (\%) } \\
\hline \multicolumn{2}{|l|}{ Age group (in years) } & \multicolumn{2}{l|}{} \\
\hline$<20$ & 39 & 10.8 \\
\hline $20-24$ & 146 & 40.44 \\
\hline $25-29$ & 83 & 22.9 \\
\hline $30+$ & 93 & 25.7 \\
\hline Mean $=26.73(\mathrm{SD}=2.53)$ & \multicolumn{2}{|l}{} \\
\hline Religion & 281 & 77.8 \\
\hline Hindu & 47 & 13.0 \\
\hline Muslim & 19 & 5.2 \\
\hline Sikh & 07 & 1.9 \\
\hline Christianity &
\end{tabular}

\begin{tabular}{|c|c|c|}
\hline Traditional & 03 & 0.8 \\
\hline Other religions & 04 & 1.1 \\
\hline \multicolumn{3}{|l|}{ Occupation } \\
\hline Unemployed & 123 & 34.0 \\
\hline Farmer & 134 & 37.1 \\
\hline Trader & 46 & 12.7 \\
\hline Civil servant & 28 & 7.7 \\
\hline Student & 19 & 5.26 \\
\hline Others & 11 & 3.04 \\
\hline \multicolumn{3}{|l|}{ Level of education } \\
\hline No education & 76 & 21.0 \\
\hline Primary & 37 & 10.4 \\
\hline Junior high school level & 196 & 54.2 \\
\hline Senior high school level and above & 52 & 14.4 \\
\hline \multicolumn{3}{|l|}{ Marital status } \\
\hline Married & 347 & 96.1 \\
\hline Separated/divorced & 11 & 3.0 \\
\hline Cohabiting & 3 & 0.8 \\
\hline \multicolumn{3}{|l|}{ Household size } \\
\hline Kaccha & 202 & 55.9 \\
\hline Pakka & 159 & 44.0 \\
\hline \multicolumn{3}{|l|}{ District of residence } \\
\hline Rural & 193 & 53.4 \\
\hline Urban & 168 & 46.5 \\
\hline \multicolumn{3}{|l|}{ Parity } \\
\hline Parity 1 & 63 & 17.4 \\
\hline Parity 2 & 127 & 35.1 \\
\hline Parity 3 & 92 & 25.4 \\
\hline Parity 3+ & 79 & 21.8 \\
\hline \multicolumn{3}{|l|}{ Delivery place } \\
\hline Hospital & 270 & 74.7 \\
\hline Home & 91 & 26.8 \\
\hline \multicolumn{3}{|l|}{ Socioeconomic Status } \\
\hline Upper & 86 & 23.8 \\
\hline Upper middle & 97 & 26.8 \\
\hline Middle & 83 & 22.9 \\
\hline Lower middle & 57 & 15.7 \\
\hline Lower & 38 & 10.5 \\
\hline
\end{tabular}

Table 2: Breast-feeding practices

\begin{tabular}{|l|l|l|}
\hline \multicolumn{2}{|l|}{ Frequency } & Proportion (\%) \\
\hline Breastfeeding type & 97 & 26.8 \\
\hline Not exclusive & 264 & 73.1 \\
\hline Exclusive & 319 & 88.3 \\
\hline When did you initiate breastfeeding? & 10.5 \\
\hline Within 6 hours & 38 & 0.8 \\
\hline $7-24$ hours & 3 & 0.2 \\
\hline $25-72$ hours & 1 & \\
\hline$<7$ days & \multicolumn{2}{|l|}{} \\
\hline How often did you breastfeed your baby in a day? \\
\hline Whenever the child cries & 237 & 65.6 \\
\hline
\end{tabular}




\begin{tabular}{|c|c|c|}
\hline Every 1 hour & 96 & 26.5 \\
\hline Every 2 hours & 21 & 5.8 \\
\hline Elders advice & 7 & 1.9 \\
\hline \multicolumn{3}{|c|}{ How long the child was given exclusive breastfeeding? } \\
\hline$<6$ months & 94 & 26.0 \\
\hline$>6$ months & 267 & 73.9 \\
\hline \multicolumn{3}{|l|}{ If $<6$ months give reasons } \\
\hline A feeling of insufficient milk & 28 & 29.7 \\
\hline Breast infection & 17 & 18.0 \\
\hline Weaning & 49 & 52.1 \\
\hline \multicolumn{3}{|l|}{ Did you discard the colostrum? } \\
\hline Yes & 78 & 21.6 \\
\hline No & 283 & 78.3 \\
\hline \multicolumn{3}{|l|}{ If yes specify reasons } \\
\hline Not good for health & 41 & 52.5 \\
\hline Elders advice & 36 & 46.1 \\
\hline Baby can't suck & 1 & 1.2 \\
\hline \multicolumn{3}{|c|}{ Prelacteal feed before starting breastfeeding } \\
\hline Yes & 69 & 19.11 \\
\hline No & 292 & 80.8 \\
\hline \multicolumn{3}{|l|}{ If yes what did you feed } \\
\hline Honey & 32 & 46.3 \\
\hline Ghutti & 23 & 33.3 \\
\hline Artificial milk & 11 & 15.9 \\
\hline Plain water & 2 & 2.8 \\
\hline Sugar water & 1 & 1.4 \\
\hline
\end{tabular}

In Table 2, Exclusive breastfeeding was practiced by $73.1 \%$ of mothers. When breastfeeding practices are assessed from mothers, $88.3 \%$ shows the initiation of breastfeeding within 6 hours of delivery. $65.6 \%$ of mothers breastfeed children whenever they cry and $26.5 \%$ breastfeed every 1 hour. $78.3 \%$ of a mother gave first breast milk i.e. colostrum to their new-borns. Still, $46.3 \%$ of mothers feed their child with honey, Ghutti, plain water, artificial milk, sugar water, etc., before starting breastfeeding.

\section{Discussion}

This study aimed was to estimate the rate and examine socio-economic and demographic determinants of breastfeeding in rural districts.

Maternal age, type of occupation, household size, and the district of residence appears to be strong determinants of breastfeeding practices. This study found factors such as mother's age, educational status, and ethnicity to be associated with among mothers. In the present study, 20-24 years were $40.4 \%$. A similar finding has also been reported by Patel A where mothers aged 25 years and above were more likely to engage in breastfeeding [11].
This could be explained as argued by Chaudhuri RN that mothers gain experience in child management as they increase in age, and in the quest of younger mothers to maintain their breast size and beauty and introduce early supplementary feeding [12].

In the present study, the religion of the mother was found to influence their practice of breastfeeding. A similar finding has been reported in a similar study by Vieira TO et al. [13]. The influence of religion on breastfeeding could be explained by the influence of cultural beliefs and practices of the various ethnic groups in India on breastfeeding practices. For instance, Gupta $P$ and colleagues have postulated that mothers mostly from the urban slums groups in Lucknow held the belief that the breast is filled with breast milk on the third day after birth which delays the initiation of breastfeeding [14].

Concerning the education of mothers in our current study who had a tertiary education were less likely to breastfeed their infants. This finding is in contrast to what has been documented in other similar studies where mothers who had informal education and/or with lower education were all less likely to exclusively breastfeed their infants [15]. Our results could be explained by Madhu $K$ the fact that mothers with higher education tend to engage in formal employment and mothers who are engaged in formal employment are less likely to breastfeed [16].

In the present study, the findings showed that mothers who were occupations such as unemployed were more likely to practice breastfeeding. This finding was in line with earlier studies that found self-employed mothers to be more likely to practice 6 months of breastfeeding [17]. This study found that mothers whose households were headed by males were more likely to practice exclusive breastfeeding but this relationship was not statistically significant after adjusting for other explanatory variables.

This result was similar to the findings of other studies in Ghana [18]. where the decision of 6 months and 24 to $26 \mathrm{~h}$ exclusive breastfeeding was influenced by spouses and family members respectively.

It was also very intriguing to find that the district of residence was significantly associated with breastfeeding practice among the study participants. Women from rural areas were $46.5 \%$ likely to practice breastfeeding compared to those from urban areas. 
This could be ascribed to the introduction of pregnancy schools in health facilities in the rural area where expectant mothers received an education, including how to look after themselves and their babies and the importance of breastfeeding. The effective rural areas where pregnant women receive antenatal care services with education on breastfeeding practices could be another contributing factor to the high likelihood of breastfeeding practice in the rural area [19].

The findings of the study suggest that $88.3 \%$ of the women initiated breastfeeding within 6 hours of delivery. Findings were comparable to the study conducted by Hiremath BR et al i.e. they found $74.29 \%$ of mothers initiated breastfeeding within 6 hours but Angadi MM et al in their study found only $42.95 \%$ of children who breastfeed within 6 hours $[20,21]$. In the present study, $65.6 \%$ of women breastfeed their child whenever they cried while $26.5 \%$ breastfeed every 1 hourly i.e. on-demand feeding was more in the present study. Sreeramareddy CT et al in their study found $42.14 \%$ of mothers breastfeed when the child cries and $44.28 \%$ every 2 hourly, higher than on-demand feeding [22]. Sohag AA et al in their study found $89.10 \%$ on-demand feeding and Shashank et al show $73.74 \%$ on-demand feeding to infants [23]. But Chakrabarty $S$ et al in their study found only $42 \%$ on-demand feeding and the rest were timely breastfed [24].

$73.9 \%$ of mothers practice exclusive breastfeeding in the present study. The main reason for discontinuation among $52.1 \%$ of study subjects was early weaning, $29.7 \%$ had feelings of insufficient milk and 18.0 had a breast infection. Aneja B et al found $80.36 \%$ of mothers followed exclusive breastfeeding in their study which is very high than the present study [25]. Chowdhury R et al in their study found $63.44 \%$ of mothers following exclusive breastfeeding even after 6 months compared to the present study [26]. The most common reason for discontinuation was insufficient milk in $49.49 \%$ of mothers.

However, the study found that about $78.3 \%$ of all mothers fed their babies with the first breast milk (colostrum). This is supported by other studies reporting $91.0 \%$ by Sankar MJ [27]. The high rates recorded in our current study could be as a result of the fact that most of the mothers delivered at the health facility, where mothers are encouraged by health personnel to breastfeed just after delivery.
$19.1 \%$ of children in the present study received prelacteal feed i.e. honey $(46.3 \%)$, some ghutti (33.3\%). artificial milk (15.9\%) before first breast milk. Results were comparable to the study conducted by Ranathunga $\mathrm{N}$ et al $(29.5 \%$ prelacteal feed) [28]. In contrast to the present study Chandra GS et al (53\%), Vyas et al $(61.8 \%)$, Ashwini et al $(57.11 \%)$ shows a high percentage of newborn received prelacteal feed before breastfeeding [29]. Swetha $R$ et al (19\%) found less percentage of the newborn who received prelacteal feed and discarded the colostrums [30].

\section{Strength and limitations of the study}

Despite the advantage of a large sample and the use of population-based data, this study has several limitations. First, the outcome was measured based on self-report; recall bias may have influenced underestimation or overestimation of the association between the outcome of interest and the explanatory variables. Social desirability bias could also be a limitation to the study as some women might have withheld what they thought to be negative aspects of their breastfeeding practices which may lead to overestimating the proportion of women who exclusively breastfed for 6 months. The study did not explore other factors such as knowledge, initiation, duration, and cultural determinants of exclusive breastfeeding which might have some influence on the outcome of interest. This was primarily due to the limited information in the secondary data used.

\section{Conclusions}

Maternal age, type of occupation, household size, and the district of residence were strong determinants of breastfeeding practices. Maintaining access to information on appropriate breastfeeding practices and promotion of breastfeeding especially among young mothers in the study area is highly recommended.

\section{What does the study add to the existing knowledge?}

To further understand other factors influencing the practice of breastfeeding and to design a suitable evidence-based intervention targeting young mothers, it is recommended further qualitative studies in this area. 


\section{Author's contribution}

Dr. Santosh Patel: Concept, study design

Dr. Kamlesh K Nigam: Manuscript preparation

Dr. G. Chitti Babu: Manuscript preparation

Dr. SLDV Ramana Murty Kadali: Proofreading

\section{Reference}

01. Victora CG, Bahl R, Barros AJD, França GVA, Horton S, Krasevec J, et al. Breastfeeding in the 21st century- epidemiology, mechanisms, and lifelong effect. Lancet. 2016;387(10017)475-90. doi: 10.1016/S0140-6736(15)01024-7 [Crossref]

02. Dibley MJ, Roy SK, Senarath U, Patel A, Tiwari $\mathrm{K}$, Agho KE, et al. Across-country comparisons of selected infant and young child feeding indi cators and associated factors in four south Asian countries. Food Nutr Bull. 2010;31(2)366-75.

doi: $10.1177 / 156482651003100224$ [Crossref]

03. Kimani-Murage EW, Madise NJ, Fotso JC, Kyobutungi C, Mutua MK, Gitau TM, et al. Patterns and determinants of breastfeeding and complementary feeding practices in urban informal settlements, Nairobi Kenya. BMC Public Health. $2011 ; 11 ; 396$.

doi: 10.1186/1471-2458-11-396 [Crossref]

04. Setegn T, Gerbaba M, Belachew T. Determinants of timely initiation of breastfeeding among mothers in Goba Woreda, south East Ethiopia- a cross sectional study. BMC Public Health. $2011 ; 11 ; 217$.

doi: $10.1186 / 1471-2458-11-217$ [Crossref]

05. Issaka AI, Agho KE, Burns P, Page A, Dibley MJ. Determinants of inadequate complementary feeding practices among children aged 6-23 months in Ghana. Public Health Nutr. 2014;18(4)669-678.

doi: $10.1017 / \mathrm{S} 1368980014000834 \quad$ [Crossref]

06. Semahegn A, Tesfaye G, Bogale A. Complementary feeding practice of mothers and associated factors in Hiwot Fana specialized hospital, eastern Ethiopia. Pan African Med J. $2014 ; 18 ; 143$.

doi: 10.11604/pamj.2014.18.143.3496 [Crossref]
07. Kabir I, Khanam M, Agho KE, Mihrshahi S, Dibley MJ, Swapan K, et al. Determinants of inappropriate complementary feeding practices in infant and young children in Bangladeshsecondary data analysis of demographic health survey 2007. Matern Child Nutr. 2012;8(1)1127.

doi: $10.1111 /$ j.1740-8709.2011.00379.x [Crossref]

08. Senarath U, Dibley MJ, Agho KE. Breastfeeding practices and associated factors among children under 24 months of age in Timor-Leste. Eur J Clin Nutr. 2007;61(3)387-397. doi: $10.1038 /$ sj.ejcn.1602536 [Crossref]

09. Ogunlesi TA. Maternal socio-demographic factors influencing the initiation and exclusivity of breastfeeding in a Nigerian semi-urban setting. Maternal Child Health J. 2010;14(3)459-65.

doi: $10.1007 / \mathrm{s} 10995-008-0440-3 \quad$ [Crossref]

10. Tan KL. Factors associated with exclusive breastfeeding among infants under six months of age in peninsular Malaysia. Int Breastfeed $\mathrm{J}$. $2011 ; 6(2)$.

doi: $10.1186 / 1746-4358-6-2$ [Crossref]

11. Patel A, Badhoniya N, Khadse S, Senarath U, Agho KE, Dible MJ. Infant and young child feeding indicators and determinants of poor feeding practices in India- secondary data analysis of National Family Health Survey 200506. Food Nutr Bull. 2010;31(2)314-333.

doi: $10.1177 / 156482651003100221 \quad$ [Crossref]

12. Chaudhuri RN, Pal I. Gender Inequalities while Rearing of Children Under Five Years in a Rural Area Of West Bengal. Indian J Comm Med. 2007;32(3)215-16.

doi: 10.4103/0970-0218.36834 [Crossref]

13. Vieira TO, Veiria GO, de Oliveira NF, Mendes MC, Giuglinia ER, Silva LR. Duration of exclusive breastfeeding in Brazilian population- a new determinant in a cohort study. BMC Pregnancy Child health. $2014 ; 14 ; 175$.

doi: 10.1186/1471-2393-14-175 [Crossref] 
14. Gupta P, Srivastava VK, Kumar V, Jain S, Massod J, Ahmad N, Srivastava JP. Newborn care practices in urban slums of Lucknow City, UP. Indian J Comm Med. 2010;35(1)82-85.

[Crossref]

15. Agho KE, Dibley MJ, Odiase JI, Ogbonmwan SM. Determinants of exclusive breastfeeding in Nigeria. BMC Pregnancy Childbirth. 2011;11;2. doi: 10.1186/1471-2393-11-2 [Crossref]

16. Madhu K, Chowdary S, Masthi R. Breast feeding practices and newborn care in rural areas- $A$ descriptive cross-sectional study. Indian J Community Med. 2009;34(3)243-246. doi: 10.4103/0970-0218.55292 [Crossref]

17. Erkkola M, Salmenhaara M, Kronberg-Kippila C, Ahonen S, Arkkola T, Uusitalo L, et al. Determinants of breast-feeding in a Finnish birth cohort. Public Health Nutr. 2010;13(4)504-13. doi: $\quad 10.1017 / \mathrm{S} 1368980009991777 \quad$ [Crossref]

18. Seid AM, Yesuf ME, Koye DN. Prevalence of exclusive breastfeeding practices and associated factors among mothers in Bahir Dar City, Northwest Ethiopia- a community based crosssectional study. Int Breastfeed J. 2013;8(1)14. doi: 10.1186/1746-4358-8-14 [Crossref]

19. Kemberling SR. Supporting breastfeeding. Paediatr. 1979;63;60-63.

[Crossref]

20. Hiremath $\mathrm{Br}$, Sorganvi V. A Cross-Sectional Study on Breast Feeding Practices in A Rural Area Of North Karnataka. IJCRR. 2013;5(21)1318.

[Crossref]

21. Angadi MM, Jawaregowda SK. Gender discrimination in relation to breast feeding practices in rural areas of Bijapur district, Karnataka. Int J Contemp Pediatr. 2015;2(4)340-344.

doi: 10.18203/2349-3291.ijcp20150970 [Crossref]

22. Sreeramareddy CT, Joshi HS, Sreekumaran B V, Giri S, Chuni N. Home delivery and newborn care practices among urban women in western Nepal- a questionnaire survey. BMC Pregnancy and Childbirth. 2006;6;27.

doi: 10.1186/1471-2393-6-27 [Crossref]
23. Sohag AA, Memon S, Rahman Ur M. Perception, Practices and factors Associated with Exclusive Breastfeeding Failure. Medical Channel. 2011;13(4)100-102.

[Crossref]

24. Chakrabarty S, Ghosh R, Bharti P. Breastfeeding Practices and Nutritional status of Preschool Children Among the Shabar Tribal community in Orissa, India. Proceedings of National Symposium Of Tribal Health, Jabalpur, India. 2006;227-234.

[Crossref]

25. Aneja B, Singh P, Tandon M, Pathak P, Singh C, Kapil U. Etiological factors of Malnutrition among infants in two urban slums of Delhi. Indian Pediatr. 2001;38(2)160-165.

[Crossref]

26. Chowdhury R, Sinha B, Sankar MJ, Taneja S, Bhandari N, Rollins $N$, et al. Breastfeeding and maternal health outcomes- a systematic review and meta-analysis. Acta Paediatr. 2015;104(467)96-113.

doi: 10.1111/apa.13102 [Crossref]

27. Sankar MJ, Sinha B, Chowdhury R, Bhandari N, Taneja S, Martines J, et al. Optimal breastfeeding practices and infant and child mortality- a systematic review and metaanalysis. Acta Paediatr. 2015;104(467)3-13. doi: 10.1111/apa.13147 [Crossref]

28. Ranathunga N, Fernando MP, Sampath W, Samaranayake GB. Actual exclusive breastfeeding rates and determinants among a cohort of children living in Gampaha district Sri Lanka- a prospective observational study. Int Breastfeed J. 2012;7(1)21. doi: 10.1186/1746-4358-7-21 [Crossref]

29. Chandra GS, Hari AS, Susheela C. Factors affecting exclusive breastfeeding, after counselling at a rural health Centre. Indian J Public Health Dev. 2015;6(2)50.

doi: $10.5958 / 0976-5506.2015 .00072 .8$ [Crossref]

30. Swetha R, Ravikumar J, Rao RN. Study of breastfeeding practices in coastal region of South India- a cross sectional study. IJCP. 2017; 1(2)74-78.

doi: 10.5455/2349-3291.ijcp20140812 [Crossref] 